\title{
Effect of formoterol with or without budesonide in repeated low-dose allergen challenge
}

\author{
B. Dahlén*,\# , A-S. Lantz*,\#, E. lhređ, M. Skedinger*,\#, E. Henriksson**, \\ L. Jörgensen ${ }^{+}$, T. Ekström ${ }^{+}$, S-E. Dahlén ${ }^{\#, \S}$ and K. Larsson ${ }^{\#, \S}$
}

ABSTRACT: The use of combination therapy in mild asthma is debated. The current authors evaluated the effects of formoterol alone and a formoterol/budesonide combination inhaler on asthma deterioration induced by repeated low-dose allergen exposure.

In total, 15 subjects with intermittent allergic asthma inhaled low doses of allergen on seven consecutive weekdays in a three-period, crossover, double-blind, double-dummy comparison between formoterol $4.5 \mu \mathrm{g}$ Turbuhaler ${ }^{\mathrm{TM}}$, budesonide $160 \mu \mathrm{g} /$ formoterol $^{4.5} \mu \mathrm{g}$ Turbuhaler $^{\mathrm{TM}}$ and placebo, each taken as two puffs $\mathbf{3 0} \mathrm{min}$ after allergen dosing. The outcome variables were: provocative dose of methacholine causing a $20 \%$ fall in forced expiratory volume in one second (PD20), exhaled nitric oxide fraction ( $F \mathrm{eNO})$, sputum eosinophils and prostaglandin $\mathrm{D}_{2}$, and diary card recordings of symptoms (on a scale of $0-10$ ), short-acting $\beta_{2}$-agonist use and evening forced expiratory volume in one second (FEV 1$)$.

With placebo treatment, allergen exposure caused significant increases in airway hyperresponsiveness (geometric mean (coefficient of variation) PD20: 397 (98) $\mu \mathrm{g}$ before versus 168 (82) $\mu \mathrm{g}$ after), FeNO (mean \pm SD $46 \pm 31$ ppb before versus $73 \pm 46$ ppb after) and asthma symptom score (mean \pm SD $0.39 \pm 0.55$ before versus $0.68 \pm 0.67$ after). Budesonide/formoterol abolished these changes and significantly improved baseline FEV1. Formoterol alone, while providing symptom relief, was no better than placebo in protecting against the allergen-induced increase in airway inflammation.

Signs of deteriorating asthma, provoked by low-dose allergen, are prevented by short-term use of budesonide/formoterol but not by temporary use of formoterol alone.

KEYWORDS: Airway hyperresponsiveness, allergic asthma, bronchoprovocation, exhaled nitric oxide, inhaled corticosteroids, long-acting $\beta$-agonists

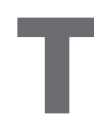
he goal for successful management of asthma is to achieve and maintain symptom control and to prevent exacerbations [1]. Subjects with intermittent asthma that is in good control may experience periodic worsening after exposure to trigger factors such as allergens, viral infections and pollutants. The deterioration is caused by progressive airway inflammation and associated with enhanced airway hyperresponsiveness [2]. Requirement of increased use of as-needed reliever medication should then prompt the patient to initiate anti-inflammatory treatment with inhaled corticosteroids (ICS) to prevent further and potentially long-lasting deterioration [1]. In practice, timely introduction of ICS often fails due to poor perception of symptoms, lack of patient education and unavailability of medical advice. Thus over-reliance on rapid-acting bronchodilators may put patients at risk by delaying proper intervention with antiinflammatory treatment. There is also a concern that use of the long-acting $\beta_{2}$-agonists (LABAs) salmeterol or formoterol, particularly as monotherapy, may render the airway inflammation progressively worse [3-5]. It has, therefore, been suggested that early use of LABAs should only occur as combination therapy with ICS [6-9]. More recently, it has also been established that combination inhalers containing both an ICS and a rapid-onset long-acting $[10,11]$ or short-acting [12] $\beta_{2}$-agonist can enable patients with persistent asthma to continuously adapt their need for

\section{AFFILIATIONS}

*Division of Respiratory Medicine and Allergy, Dept of Medicine, Karolinska University Hospital Huddinge,

${ }^{*}$ Centre for Allergy Research, Karolinska Institutet,

${ }^{\S}$ Division of Physiology, The National Institute of Environmental Medicine, Karolinska Institutet,

- Cityakuten, Stockholm, and ${ }^{+}$AstraZeneca Sweden, Södertälje, Sweden.

CORRESPONDENCE

B. Dahlén

Lung and Allergy Clinic, M 53 , Karolinska University Hospital Huddinge,

SE-141 86 Stockholm, Sweden Fax: 4687117306 E-mail: barbro.dahlen@ki.se

Received:

June 242008

Accepted after revision:

November 232008

\section{SUPPORT STATEMENT}

This study received financial support from AstraZeneca Sweden, the Karolinska Institutet, the Centre for Allergy Research and the Stockholm County Council (ALF), and the following Swedish foundations: the Heart Lung Foundation, the Association Against Asthma and Allergy, and the Medical Research Council (grant 74X-15067).

STATEMENT OF INTEREST Statements of interest for S-E. Dahlén and K. Larsson, and the study itself, can be found at

www.erj.ersjournals.com/misc/ statements.dtl 
anti-inflammatory treatment according to fluctuations in their disease. So far, only one study has addressed the use of asneeded combination therapy in intermittent asthma [13]. The rationale for this strategy in patients whose asthma is mostly well controlled thus merits further consideration, since airway inflammation has been shown to be a characteristic feature even in very mild disease [14, 15].

Repeated low-dose allergen inhalation challenge has been introduced as a method to mimic and standardise natural exposure to environmental allergens $[16,17]$. In this challenge setting, patients with allergic asthma inhale fixed doses of allergen that are titrated to cause minimal bronchoconstriction and administered once daily on between four and 10 consecutive weekdays $[17,18]$. The procedure generates increased airway hyperresponsiveness to direct bronchoconstrictors and elevations in exhaled nitric oxide fraction ( $F$ eNO) and in inflammatory markers in sputum $[17,18]$. This occurs despite only few symptoms of asthma being reported by the subjects. Hence, the challenge model is particularly suitable to investigate early events in the development of more symptomatic asthma.

The present study is the first to employ the repeated low-dose allergen challenge setting to investigate the effects of either formoterol alone or its fixed combination with budesonide on indices of asthma deterioration that are associated with very mild or no symptoms. The study was conducted as a crossover, double-blind, double-dummy, three-period comparison between formoterol, budesonide/formoterol in a combination inhaler and placebo in subjects with intermittent asthma. All treatments were administered throughout the course of allergen exposure and their effects on airway responsiveness to methacholine, pulmonary function, symptoms, levels of
FeNO, sputum eosinophils and prostaglandin $(\mathrm{PG}) \mathrm{D}_{2}$ in sputum (as a mast cell marker) were investigated.

\section{METHODS}

An extended version of the methods is available in the online supplementary material.

\section{Subjects}

In total, 15 nonsmoking subjects with intermittent allergic asthma [1] treated only with a short-acting $\beta_{2}$-agonist p.r.n. participated. All had a post-bronchodilator forced expiratory volume in one second (FEV1) $>80 \%$ of predicted normal value and airway hyperresponsiveness to methacholine (table 1). Exclusion criteria were significant allergen exposure, chronic obstructive pulmonary disease or any significant respiratory disease other than asthma, a respiratory tract infection within 4 weeks and use of glucocorticosteroids within 2 months prior to the study.

The Ethics Committee at The Karolinska University Hospital (Stockholm, Sweden) approved the study (Dnr 04-470/1-4) and the subjects gave written informed consent.

\section{Study design}

The present study (NCT00288379) was a three-period, crossover, double-blind, double-dummy comparison (in random order) between formoterol $4.5 \mu \mathrm{g}$ Turbuhaler ${ }^{\mathrm{TM}}$, budesonide $160 \mu \mathrm{g} /$ formoterol $4.5 \mu \mathrm{g}$ Turbuhaler ${ }^{\mathrm{TM}}$ and placebo (AstraZeneca, Lund, Sweden) on airway functional and inflammatory changes and symptoms, induced by repeated low-dose allergen exposure (fig. 1). The study medication was taken as two puffs $30 \mathrm{~min}$ after allergen inhalation on every low-dose challenge day.

\section{TABLE 1 Subject characteristics at screening}

\begin{tabular}{|c|c|c|c|c|c|c|c|c|}
\hline Subject & Sex & Age yrs & FEV $1 \%$ pred & MCh-PD20 $\mu \mathrm{g}$ & Allergen & $\begin{array}{l}\text { Allergen-PD20 } \\
\text { SQ units }\end{array}$ & $\begin{array}{l}\text { Low-dose allergen-PD5 } \\
\text { SQ units }\end{array}$ & FeNO ppb \\
\hline 2 & M & 25 & 113 & 728 & Cat & 310 & 42 & 77.2 \\
\hline 3 & $\mathrm{~F}$ & 23 & 114 & 1082 & Cat & 1836 & 213 & 50.8 \\
\hline 4 & M & 19 & 113 & 538 & Cat & 1991 & 355 & 25.0 \\
\hline 7 & $\mathrm{~F}$ & 36 & 113 & 53 & Cat & 3172 & 426 & 50.8 \\
\hline 8 & M & 22 & 111 & 1511 & Cat & 1174 & 355 & 25.2 \\
\hline 9 & M & 19 & 103 & 220 & Timothy & 34 & 14 & 98.2 \\
\hline 10 & $\mathrm{~F}$ & 25 & 91 & 346 & Dog & 475 & 70 & 76.2 \\
\hline 11 & M & 55 & 91 & 93 & Birch & 128 & 35 & 28.8 \\
\hline 12 & M & 39 & 105 & 1574 & Timothy & 804 & 142 & 17.1 \\
\hline
\end{tabular}

FEV1: forced expiratory volume in one second; \% pred: \% predicted; MCh-PD20: provocative dose of methacholine causing a 20\% fall in FEV1; allergen-PD20: provocative dose of allergen causing a $20 \%$ fall in FEV1; SQ: standardised quality; allergen-PD5: provocative dose of allergen causing a $5 \%$ fall in FEV 1 ; FeNO: exhaled nitric oxide fraction; M: male; F: female. 


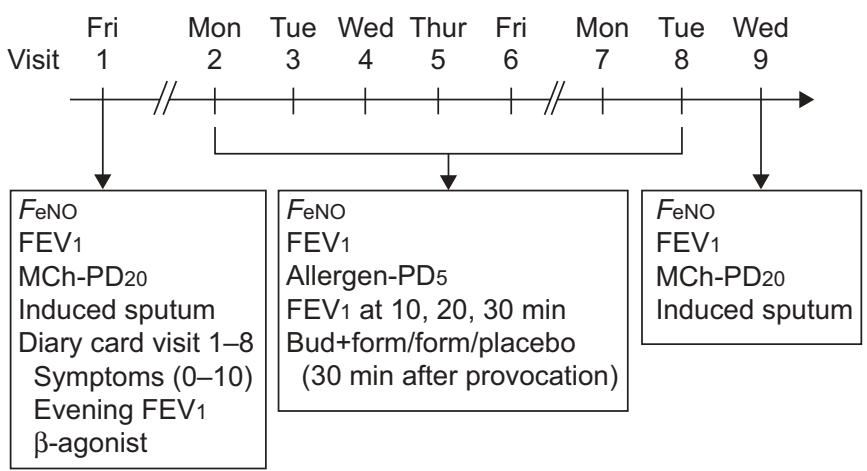

FIGURE 1. Design of study. FeNO: exhaled nitric oxide fraction; FEV 1 : forced expiratory volume in one second; MCh-PD20: provocative dose of methacholine causing a $20 \%$ fall in $\mathrm{FEV} 1$; allergen-PD5: provocative dose of allergen causing a $5 \%$ fall in $\mathrm{FEV}_{1}$; bud: budesonide; form: formoterol.

The subjects participated in two screening visits prior to randomisation, which included a skin prick test, pre-study spirometry, a methacholine challenge and a cumulative, highdose allergen inhalation challenge to establish current sensitivity, expressed as the provocative dose of allergen causing a $20 \%$ fall in FEV1 (allergen-PD20) [19]. See online supplementary material.

Each period consisted of nine clinic visits, always in the morning, with methacholine challenges and induced sputum collection (see online supplementary material) on visit days 1 and 9, i.e. pre- and post-repeated allergen exposure period. FeNO (NIOX ${ }^{\mathrm{TM}}$; Aerocrine AB, Stockholm, Sweden) and FEV1 (Jaeger MasterScope; IntraMedic Inc., Bålsta, Sweden) were measured daily according to current recommendations [20,21] and the values obtained before methacholine challenge on visit day 1 were taken as pre-allergen exposure, pre-treatment baseline in the respective period.

Allergen (Aquagen ${ }^{\mathrm{TM}}$; ALK Laboratories, Copenhagen, Denmark) was inhaled as a single dose on seven consecutive weekdays, i.e. Monday-Friday one week plus Monday and Tuesday the next week (visit days 2-8; fig. 1). The allergen dose selected as the low dose was calculated from the screening allergen challenge as the cumulative provocative dose of allergen causing a 5\% fall in FEV1 from post-diluent value (allergen-PD5; table 1). Spirometry was obtained before and 10, 20 and $30 \mathrm{~min}$ after allergen inhalation on each occasion. The randomised study treatment was then inhaled under observation before the subject was allowed to leave the clinic.

Diary cards were administered on day 1 in each period and the subjects were asked to record their symptom score on a visual analogue scale $(0-10)$ and their use of short-acting $\beta$-agonist, every evening covering the previous $24 \mathrm{~h}$. In addition, evening measurements of FEV1 were recorded at home using a pocket spirometer (Spirobank ${ }^{\mathrm{TM}}$; IntraMedic Inc.).

The three periods were separated by a 15-day washout, which was extended to a maximum of 8 weeks in the case of remaining asthma deterioration after the previous exposure period, or an interfering respiratory tract infection. All study visits were scheduled outside season in pollen-sensitised subjects.

\section{Statistical analysis}

Within-period changes and treatment differences in logtransformed PD20, FEV1 and FeNO values and diary card data were analysed using a repeated measures ANCOVA model, with subject, period and treatment as factors, and with baseline pre-allergen, pre-treatment values in each period as covariate. Data are presented as adjusted least square (LS) means (or geometric means for PD20) and 95\% confidence interval (CI). Period and carry-over effects of the drug treatments were analysed by substituting treatment with period and calculating trends throughout the study. The sample size was calculated to be 12 completed patients assuming a standard deviation of $\log _{10}$-transformed PD20 of 0.23 , a significance level of $5 \%$, an $80 \%$ power, a two-sided alternative hypothesis and a betweentreatment difference (increase) of $83 \%$ in PD20. Differences were considered significant if $\mathrm{p}<0.05$.

\section{RESULTS}

There were no period or carry-over effects of the treatments (see online supplementary material).

\section{Airway responsiveness to methacholine}

During placebo treatment, repeated low-dose allergen exposure produced an increase in airway hyperresponsiveness to methacholine, with a significant reduction in geometric mean PD20 (397 $\mu \mathrm{g}$ before versus $168 \mu \mathrm{g}$ after the exposure period). The reduction corresponded to -1.28 doubling doses (95\% CI -2.1- $-0.49 ; \mathrm{p}=0.01$ as LSmean change; fig. 2). In contrast, budesonide/formoterol completely prevented allergeninduced deterioration in airway hyperresponsiveness, with a higher post-allergen methacholine-PD20 (383 $\mu \mathrm{g}$ before versus $660 \mu \mathrm{g}$ after) corresponding to 0.72 doubling doses $(95 \% \mathrm{CI}$ $-0.07-1.51 ; p=0.07)$. There was no significant change in airway hyperresponsiveness during formoterol treatment, with a

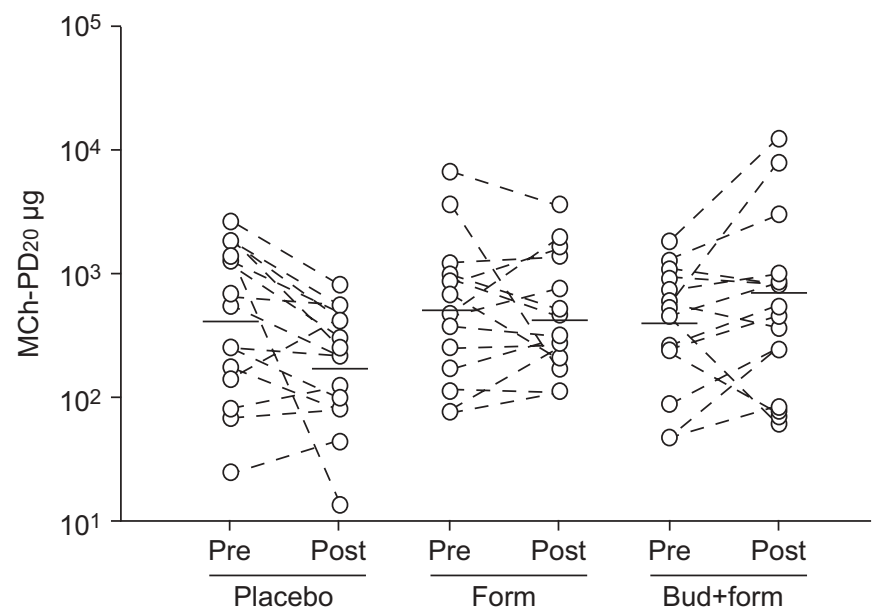

FIGURE 2. Individual $(\bigcirc)$ and geometric mean $\left(--_{-}\right)$shift in airway responsiveness to methacholine expressed as provocative dose of methacholine causing a $20 \%$ fall in forced expiratory volume in one second (MCh-PD20) before versus after 7 days of allergen exposure, in a three-period, crossover, double-blind, randomised treatment study with placebo, formoterol (form) and budesonide (bud)/ formoterol. During placebo treatment, there was an increase in airway hyperresponsiveness $(p=0.01)$, which was inhibited with budesonide/formoterol $(p=0.01$ compared with placebo) but not with formoterol alone. 
geometric mean PD20 $483 \mu \mathrm{g}$ before and $401 \mu \mathrm{g}$ after allergen exposure (-0.17 doubling dose, 95\% CI -0.95-0.63; $\mathrm{p}=0.67)$.

While there was no variability in pre-exposure methacholine responsiveness between the three periods, comparison between treatments demonstrated significant protection by budesonide/formoterol corresponding to 2.7 doubling doses versus placebo (95\% CI 1.3-5.5; $\mathrm{p}=0.01)$, whereas treatment with formoterol was not statistically significant different from placebo (formoterol versus placebo 1.75 doubling dose, 95\% CI $0.9-3.5 ; \mathrm{p}=0.11)$. Formoterol/budesonide was quantitatively better than formoterol (1.55 doubling dose) but the difference did not reach statistical significance (95\% CI 0.7-3.2; $\mathrm{p}=0.22)$.

Correction for drug effects on baseline FEV1 in the statistical analysis did not alter the results of the airway hyperresponsiveness assessments (not shown). Furthermore, the change in methacholine-PD20 did not correlate with initial airway responsiveness to methacholine, allergen sensitivity, baseline symptom score or FeNO.

\section{FeNO}

There was a progressive rise in the concentrations of $\mathrm{NO}$ in exhaled air during the placebo-treated allergen exposure (fig. 3), with an adjusted LSmean (95\% CI) increase over the exposure period amounting to 25.7 (8.8-42.6) ppb ( $\mathrm{p}=0.006)$. Notably, the levels fell after the weekend pause in exposure, but were raised again when the patients were re-exposed for an additional 2 days (fig. 3). The allergen-induced rise in FeNO levels was not inhibited during treatment with formoterol (adjusted LSmean change $22.1 \mathrm{ppb}, 95 \% \mathrm{CI} 5.2-39.0 \mathrm{ppb} ; \mathrm{p}=0.014)$, and the response was closely similar to that of the placebo treatment (fig. 3). In contrast, budesonide/formoterol abolished the allergen-induced rise in $F$ eNO concentrations (adjusted LSmean change 7.6 ppb, 95\% CI -9.3-24.6 ppb; $\mathrm{p}=0.35$ ).

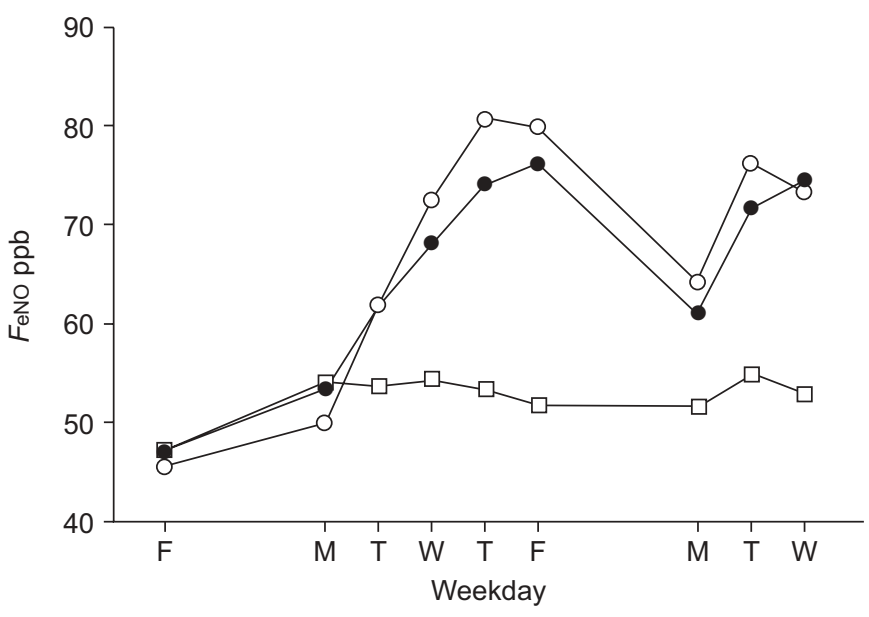

FIGURE 3. Mean exhaled nitric oxide fraction ( $F_{\mathrm{eNO}}$ ) during 7 days of allergen exposure (Monday-Friday plus Monday-Tuesday) in a three-period, crossover, double-blind, randomised treatment study with placebo $(\bigcirc)$, formoterol $(\bullet)$ and budesonide/formoterol $(\square)$. In the presence of placebo and formoterol, the levels of FeNO increased progressively, whereas budesonide/formoterol offered significant protection ( $p=0.0002$ versus placebo).
When comparing budesonide/formoterol with placebo and formoterol, the differences were highly significant, with the adjusted LSmean $(95 \% \mathrm{CI})$ being $-18(-26--10) \mathrm{ppb}(\mathrm{p}=0.0002)$ and -14.4 (-22- -6.4) ppb $(\mathrm{p}=0.0017)$, respectively. As displayed in figure 3 , there was no difference between treatment with placebo and formoterol alone (adjusted LSmean 3.6 (-411.2) $\mathrm{ppb} ; \mathrm{p}=0.33$ ) on the allergen-induced rise in FeNO.

\section{Sputum measurements}

Eosinophilic granulocytes in induced sputum increased post allergen challenge following formoterol treatment, but not after placebo or budesonide/formoterol treatment (fig. 4a). There was a statistically significant difference between budesonide/formoterol and formoterol alone $(p=0.016)$, while other group comparisons did not show significant differences.

Levels of $\mathrm{PGD}_{2}$ likewise increased following formoterol treatment but not significantly after placebo nor budesonide/ formoterol (fig. 4b).
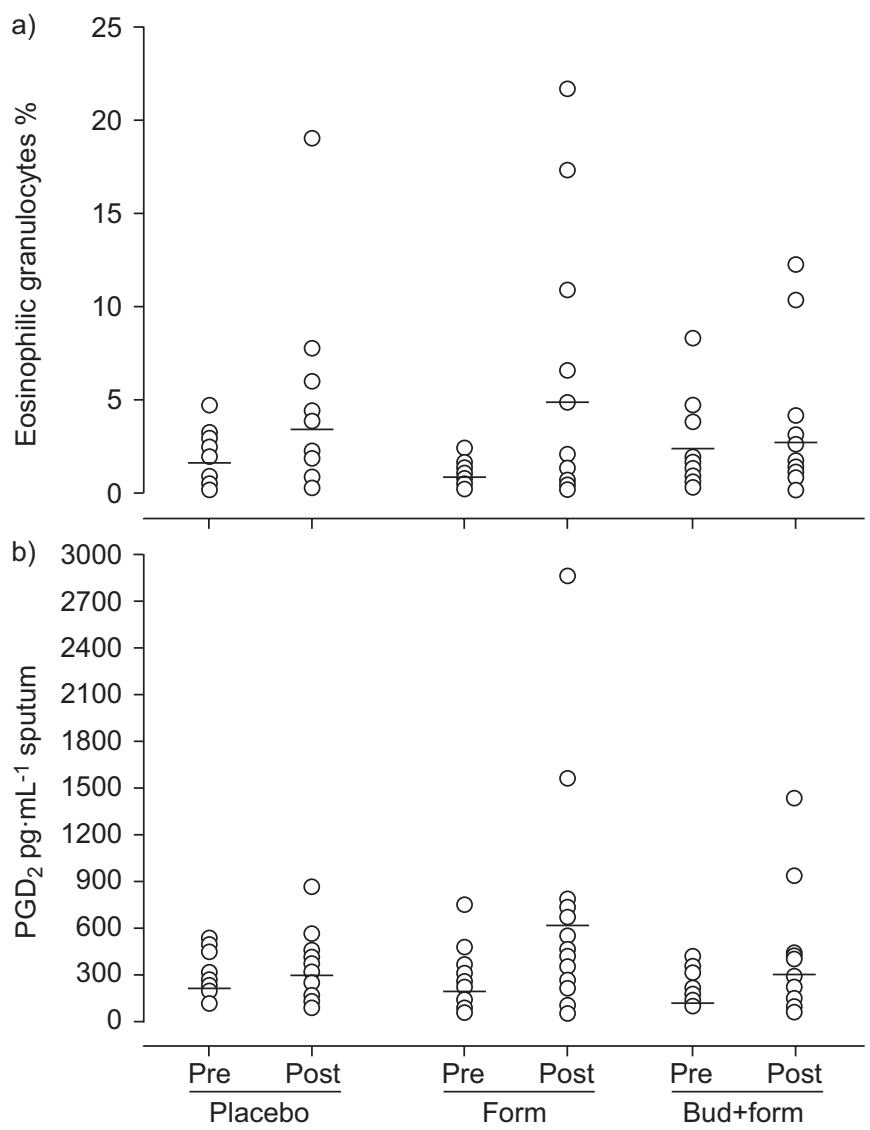

FIGURE 4. Individual and mean changes of a) per cent eosinophilic granulocytes and b) concentrations of prostaglandin $(P G) D_{2}$ in induced sputum before versus after 7 days of allergen exposure and concomitant treatment with placebo, formoterol (form) and budesonide (bud)/formoterol. With formoterol, significant increases of sputum eosinophilic granulocytes $(p=0.048)$ as well as of $\mathrm{PGD}_{2}$ concentrations $(p=0.005)$ were seen. With placebo or budesonide/ formoterol, there were no statistically significant increases of either inflammatory biomarker. However, with placebo, the $\mathrm{PGD}_{2}$ concentrations were close to significance $(p=0.060)$ 


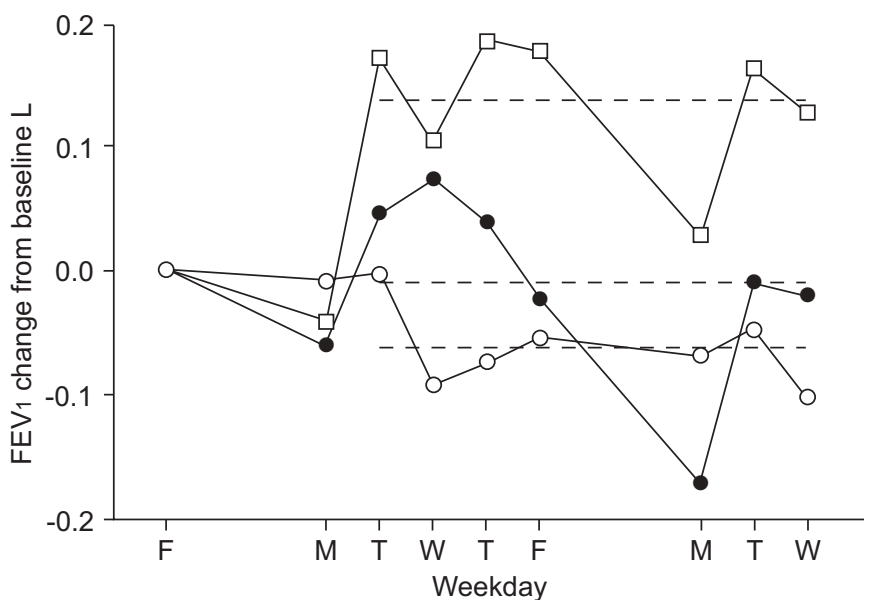

FIGURE 5. Change from baseline in forced expiratory volume in one second (FEV1) during 7 days of allergen exposure (Monday-Friday plus Monday-Tuesday) and concomitant treatment with placebo $(\bigcirc)$, formoterol $(\bullet)$ and budesonide/ formoterol $(\square)$. - - - : mean change for each treatment. Daily baseline FEV1 values (prior to a repeat allergen dose) improved with budesonide/formoterol $(p=0.002$ versus placebo), but not with formoterol, during allergen challenge.

\section{Lung function}

The effect of repeated low-dose allergen exposure on morning baseline FEV1 measurements is displayed in figure 5. The adjusted LSmean (95\% CI) change of FEV1, including all measurements in the treatment period (Friday before allergen exposure (visit 1$)$ versus mean of visits $3-9)$, was $-0.08(-0.18-$ $0.02) \mathrm{L}$ for placebo $(p=0.10),-0.02(-0.12-0.08) \mathrm{L}$ for formoterol $(p=0.64)$ and $0.14(0.04-0.25) \mathrm{L}$ for budesonide/formoterol $(\mathrm{p}=0.01)$. Thus, baseline FEV1 (prior to a repeat allergen dose) improved with budesonide/formoterol during the challenge period, but not with formoterol or placebo.

As a corollary, budesonide/formoterol was significantly superior to treatment with placebo or formoterol on changes in baseline lung function measurements, the adjusted LSmean differences $(95 \% \mathrm{CI})$ being $0.23(0.1-0.35) \mathrm{L}(\mathrm{p}=0.002)$ and 0.17 (0.04-0.3) L $\quad(p=0.015)$, respectively (fig. 4). Comparison between placebo and formoterol showed no significant difference $(-0.06(-0.18-0.07) \mathrm{L} ; \mathrm{p}=0.33)$.

The mean \pm SD immediate fall in FEV1 within 30 min after lowdose allergen inhalation (before intake of study medication) was $7.79 \pm 1.19,7.20 \pm 1.60$ and $6.93 \pm 1.62 \%$ during the treatment periods with placebo, budesonide/formoterol and formoterol, respectively. There was no difference between treatments and no progressiveness over time in the magnitude of immediate responses.

\section{Asthma symptoms, $\boldsymbol{\beta}_{\mathbf{2}}$-agonist usage and evening FEV 1}

Diary card recordings revealed an increase of the average symptom score during placebo treatment (adjusted LSmean change (95\% CI): $0.31(0.12-0.49) ; \mathrm{p}=0.003)$ compared with budesonide/formoterol (0.1 (-0.1-0.28); $\mathrm{p}=0.27)$ and formoterol (0.1 (-0.1-0.28); $\mathrm{p}=0.29)$ treatments (fig. 6). Accordingly, between-treatment comparisons showed significant protection from symptoms by budesonide/formoterol and formoterol alone (adjusted LSmean difference (95\% CI) -0.21(-0.38- -0.03), $\mathrm{p}=0.024$, for budesonide/formoterol versus placebo; and

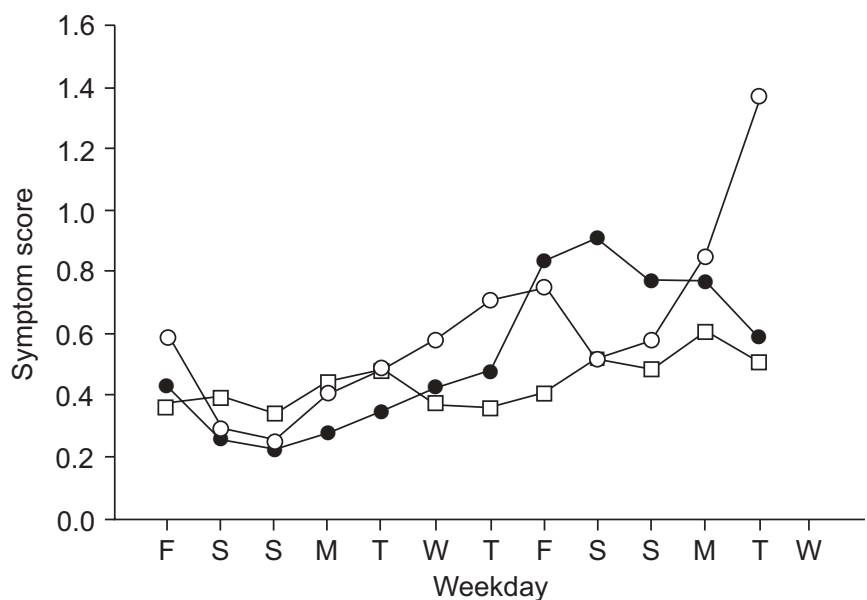

FIGURE 6. Mean asthma symptom score (0-10) recorded every evening during 7 days of allergen exposure (Monday-Friday plus Monday-Tuesday). In the presence of placebo $(\bigcirc)$ there was an increase in symptom score $(p=0.003)$, whereas both budesonide/formoterol $(\square)$ and formoterol alone (-) provided protection ( $p=0.024$ and $p=0.021$, respectively).

$-0.21(-0.38--0.04), p=0.021$, for formoterol versus placebo) with no difference between the two active treatments.

As-needed use of $\beta_{2}$-agonist was infrequent, with no difference between treatments and a total number over each exposure period of 24, 14 and 11 puffs for placebo, budesonide/ formoterol and formoterol, respectively. There were also no significant changes or between-treatment differences in evening recordings of FEV1 at home (not shown), although a trend for protection by budesonide/formoterol versus placebo was observed $(p=0.09)$.

\section{DISCUSSION}

In the present three-period, crossover treatment study in 15 subjects with intermittent asthma, repeated low-dose allergen exposure in the presence of placebo produced significant increases in airway hyperresponsiveness, FeNO and symptom score. Treatment with formoterol alone inhibited the rise in symptoms, but provided no protection against allergen-induced airway inflammation. In contrast, budesonide/formoterol abolished all of these components of asthma deterioration and, moreover, improved baseline pulmonary function.

The current study is the largest three-period, double-blind, crossover treatment study performed in the repeated low-dose allergen challenge setting. The current protocol using allergenPD5 as the target dose administered for seven consecutive weekdays was successfully employed. The placebo-treated challenge elicited a mean immediate fall in FEV1 of $<8 \%$ and generated significant increases in the main outcome variables, airway hyperresponsiveness, symptom score and FeNO. The exquisite sensitivity of FeNO measurements as a surrogate marker of the allergen-induced airway inflammation was particularly evident (fig. 3) [17, 20]. Conversely, there was no significant deterioration in morning FEV1, patient-recorded $\beta_{2^{-}}$ agonist usage or evening lung function measurements at home. Analyses of period and carry-over effects confirmed that the 15-day washout periods were long enough (see online supplementary material). Accordingly, the baselines were very 
similar for all outcome variables and statistical calculations yielded the same final results irrespective of adjustments for baseline differences. With a three-period design and 4 days of allergen-PD5 exposure, GAUVREAU et al. [18] demonstrated sufficient washout with 1 week.

The drop-out rate in the present study was less than expected, with all 15 subjects who managed the first period completing the study. Out of the 17 subjects who entered the treatment phase, one was withdrawn early in the first period due to an unacceptable increase in allergen sensitivity compared with screening, and another was withdrawn because of disc hernia. Of the completing patients, only three subjects had prolongations of washout periods due to common colds or, in one case, markedly increased methacholine responsiveness after the placebo-treated period. Therefore, the current authors believe their protocol for repeated low-dose allergen exposure to be robust and appropriate for use in future intervention studies.

The study medication was always administered under observation $30 \mathrm{~min}$ after inhalation of the allergen dose. This particular time-point was selected with the intention to mimic the situation of temporary exposure to allergen when patients start to perceive mild symptoms or become aware of the presence of allergen in the environment. Moreover, the supervised administration of study treatment provided full compliance, and the possibly confounding effect of acute bronchodilation before allergen inhalation was avoided.

Budesonide/formoterol combination therapy provided effective protection against the increase in airway hyperresponsiveness, airway inflammation assessed as FeNO and symptom score, i.e. the elemental components of asthma, despite being administered after allergen exposure. These protective effects of budesonide/formoterol against allergen exposure were observed despite the fact that the study subjects were judged not to require regular treatment with inhaled glucocorticosteroids. The improvement in lung function by budesonide/ formoterol did not, however, contribute to the reduction in airway hyperresponsiveness, since correction for baseline FEV1 in the statistical analysis did not alter the result.

Formoterol provided relief of symptoms when administered alone and was quantitatively better than placebo in protecting against allergen-induced increase in bronchial hyperresponsiveness, but produced no improvement in morning baseline lung function. In addition, an increase in sputum eosinophils was seen during formoterol treatment and the rise in FeNO was identical to that with placebo. Moreover, the marker of mast cell activation, $\mathrm{PGD}_{2}$, also increased significantly in sputum following treatment with formoterol alone. By providing symptom relief but allowing the underlying inflammation to persist or even worsen, formoterol thereby masked the signs of asthma deterioration.

The budesonide component of budesonide/formoterol has been studied in the repeated low-dose model previously [18, 22]. Budesonide $400 \mu \mathrm{g}$ administered once daily before allergen inhalation prevented the rise in allergen-induced airway hyperresponsiveness [18], sputum eosinophilia [18, 22] and FeNO [22]. However, in previous studies, no comparison with a $\beta_{2}$-agonist was done. Since in real life the patients' first treatment is their $\beta_{2}$-agonist, and because of the mounting use of the rapid-acting long-lasting formulation, formoterol, as well as the budesonide/formoterol combination therapy, this provided the rationale for selecting these particular two drugs for investigation.

From a general perspective, the present study was designed to address more in depth two treatment options at the crossing point between the first two steps in the current guidelines for asthma management [1]. This is where patients with intermittent asthma are told to add regular use of an ICS on the basis of increasing asthma symptoms or, conversely, if they are well controlled with no symptoms and normal lung function they may step back from the daily use of ICS. The number of possibilities for a personalised treatment in patients with mild persistent asthma was recently highlighted [23, 24]. Large treatment studies are needed to address at which stage the combination inhalers, containing ICS and $\beta_{2}$-agonists with various duration and onset of action, are to be introduced in the evolution of asthma. Current guidelines emphasise that frequent use of $\beta_{2}$-agonist on demand should always be accompanied with regular use of an ICS. For the large group of patients who are to be found in the interface between intermittent and mild persistent asthma, this caveat may, however, very well be forgotten.

The present study provides support for the use of the combination inhaler budesonide/formoterol to gain control when intermittent asthma starts to worsen. In contrast, while providing symptom relief but no protection against underlying features of asthma deterioration, the results with formoterol alone are indicative of a risk for masking of inflammation and potential asthma worsening if incorrectly used as monotherapy.

\section{ACKNOWLEDGEMENTS}

The authors are grateful for the excellent technical assistance from the following: M. Eduards, A. Gülich (both Division of Respiratory Medicine and Allergy, Dept of Medicine, Karolinska University Hospital Huddinge, and Centre for Allergy Research, Karolinska Institutet, Stockholm, Sweden), J. Larsson (Division of Physiology, The National Institute of Environmental Medicine, and Centre for Allergy Research, Karolinska Institutet, Stockholm) and F. Hargreave (Asthma Research Group, Firestone Institute for Respiratory Health, St Joseph's Healthcare and Hamilton Health Sciences, McMaster University, Hamilton, ON, Canada).

\section{REFERENCES}

1 Global Initiative for Asthma. Global Strategy for Asthma Management and Prevention: NHLBI/WHO workshop report. Bethesda, National Heart Lung and Blood Institute, 2006. Available from www.ginasthma.org.

2 Bousquet J, Jeffery PK, Busse WW, Johnson M, Vignola AM. Asthma. From bronchoconstriction to airways inflammation and remodeling. Am J Respir Crit Care Med 2000; 161: 1720-1745.

3 Lazarus SC, Boushey HA, Fahy JV, et al. Long-acting $\beta_{2^{-}}$ agonist monotherapy $v s$ continued therapy with inhaled corticosteroids in patients with persistent asthma: a randomized controlled trial. JAMA 2001; 285: 2583-2593.

4 Nelson HS, Weiss ST, Bleecker ER, Yancey SW, Dorinsky PM, SMART Study Group, The Salmeterol 
Multicenter Asthma Research Trial: a comparison of usual pharmacotherapy for asthma or usual pharmacotherapy plus salmeterol. Chest 2006; 129: 15-26.

5 Pauwels RA, Sears MR, Campbell M, et al. Formoterol as relief medication in asthma: a worldwide safety and effectiveness trial. Eur Respir J 2003; 22: 787-794.

6 Greening AP, Ind PW, Northfield M, Shaw G. Added salmeterol versus higher-dose corticosteroid in asthma patients with symptoms on existing inhaled corticosteroid. Allen \& Hanburys Limited UK Study Group. Lancet 1994; 344: 219-224.

7 Woolcock A, Lundback B, Ringdal N, Jacques LA. Comparison of addition of salmeterol to inhaled steroids with doubling of the dose of inhaled steroids. Am J Respir Crit Care Med 1996; 153: 1481-1488.

8 Pauwels RA, Löfdahl CG, Postma DS, et al. Effect of inhaled formoterol and budesonide on exacerbations of asthma. Formoterol and Corticosteroids Establishing Therapy (FACET) International Study Group. N Engl J Med 1997; 337: 1405-1411.

9 O'Byrne P, Barnes PJ, Rodriguez-Roisin R, et al. Low dose inhaled budesonide and formoterol in mild persistent asthma: the OPTIMA randomized trial. Am J Respir Crit Care Med 2001; 164: 1392-1397.

10 O'Byrne PM, Bisgaard H, Godard PP, et al. Budesonide/ formoterol combination therapy as both maintenance and reliever medication in asthma. Am J Respir Crit Care Med 2005; 171: 129-136.

11 Rabe KF, Atienza T, Magyar P, Larsson P, Jorup C, Lalloo UG. Effect of budesonide in combination with formoterol for reliever therapy in asthma exacerbations: a randomised controlled, double-blind study. Lancet 2006; 368: 744-753.

12 Papi A, Canonica GW, Maestrelli P, et al. Rescue use of beclomethasone and albuterol in a single inhaler for mild asthma. N Engl J Med 2007; 356: 2040-2052.

13 Haahtela T, Tamminen K, Malmberg LP, et al. Formoterol as needed with or without budesonide in patients with intermittent asthma and raised NO levels in exhaled air: a SOMA study. Eur Respir J 2006; 28: 748-755.

14 Laitinen LA, Laitinen A, Haahtela T. Airway mucosal inflammation even in patients with newly diagnosed asthma. Am Rev Respir Dis 1993; 147: 697-704.
15 Jeffery PK, Godfrey RW, Adelroth E, Nelson F, Rogers A Johansson SA. Effects of treatment on airway inflammation and thickening of basement membrane reticular collagen in asthma. A quantitative light and electron microscopic study. Am Rev Respir Dis 1992; 145: 890-899.

16 Ihre E, Zetterström O. Increase in non-specific bronchial responsiveness after repeated inhalation of low doses of allergen. Clin Exp Allergy 1993; 23: 298-305.

17 Ihre E, Gyllfors P, Gustafsson LE, Kumlin M, Dahlén B. Early rise in exhaled nitric oxide and mast cell activation in repeated low-dose allergen challenge. Eur Respir J 2006; 27: 1152-1159.

18 Gauvreau GM, Sulakvelidze I, Watson RM, Inman MD, Rerecich TJ, O'Byrne PM. Effects of once daily dosing with inhaled budesonide on airway hyperresponsiveness and airway inflammation following repeated low-dose allergen challenge in atopic asthmatics. Clin Exp Allergy 2000; 30: 1235-1243.

19 Roquet A, Dahlén B, Kumlin M, et al. Combined antagonism of leukotrienes and histamine produces predominant inhibition of allergen-induced early and late phase airway obstruction in asthmatics. Am J Respir Crit Care Med 1997; 155: 1856-1863.

20 Recommendations for standardized procedures for the online and off-line measurement of exhaled lower respiratory nitric oxide and nasal nitric oxide in adults and children 1999. This official statement of the American Thoracic Society was adopted by the ATS Board of Directors, July 1999. Am J Respir Crit Care Med 1999; 160: 2104-2117.

21 Standardization of Spirometry, 1994 update. American Thoracic Society. Am J Respir Crit Care Med 1995; 152: 1107-1136.

22 de Kluijver J, Evertse CE, Schrumpf JA, et al. Asymptomatic worsening of airway inflammation during low-dose allergen exposure in asthma: protection by inhaled steroids. Am J Respir Crit Care Med 2002; 166: 294-300.

23 Kraft M, Israel E, O'Connor GT. Clinical Decisions. Treatment of mild persistent asthma. N Engl J Med 2007; 356: 2096-2100.

24 American Lung Association Asthma Clinical Research Centers, Peters SP, Anthonisen N, et al. Randomized comparison of strategies for reducing treatment in mild persistent asthma. N Engl J Med 2007; 356: 2027-2039. 